\title{
How do you Stay Healthy and fit in Prison
}

\author{
*Mr.Dhivagar S, **Ms.Jayasri J \&***Ms.Santhiya $V$
}

\begin{abstract}
:
Highest attainable standard of physical and mental health is a fundamental human right of the every human being without discrimination. However, the Prisoners suffer a disproportionate burden of health problems as their health needs are often neglected. The concept of care, positive expectations and respect should permeate all prisons. In addition to providing health care, Prison should provide synergistic health education, patient education, prevention and other health promotion interventions to meet the assessed needs of the prison population. The healthy prison compile of standardized health facilities based on the inmate's needs.
\end{abstract}

\section{INTRODUCTION}

Prison, correctional facility, detention center, Jail, Gaol, or remand Centre is facility in which inmates are forcibly confined and denied variety of freedoms under the authority of the state.(1)Prisoners with existing health care conditions may have their health needs ignored or neglected, and others may develop health problems whilst in prison due to unhealthy and unhygienic prison conditions and poor control of infectious diseases.(11)

The healthy prison compile of standards of health facilities based on the inmates needs. Such as

- Primary health care in prison

- Standards in prison health,

- Substitution treatment in prisons

- Mental health,

- Dental health,

- Special health requirements for female prisoners.

\section{PRIMARY HEALTH CARE IN PRISON:}

- Prison is a special setting for primary health care. All prison health services should strive to provide prisoners with health care equivalent to that provided in the community.

- The main purpose of health care is patient care, and prison health care is no different.

- Health professionals should understand and seek to minimize the negative effects of the experience of prison and use opportunities that prison can offer to benefit their patients.

- The primary care services should understand the justice and health policy and the structures in which they work and seek to link with local services and resources

- Every prison should have medical, nursing, dental, psychological and pharmacy services, with administrative support

- Every prison should have access to health services at all hours 
- Every prison should maintain a system to health services at all hours

- Primary health care in prison is important for the well-being of the patients, all prisoners and the community, the effectiveness of prison services and the public health of the community(2).

\section{STANDARDS IN PRISON HEALTH}

- The relationship between the prisoner and health care team, all health care staff members who work in prisons must always remember that their first duty to any prisoner who is their patient is clinical.

- This is underlined in the first of the United Nations (1982) Principles of Medical Ethics relevant to the role of Health Personnel, Particularly Physicians; in the protection of prisoners are Detainees against Torture and Other Cruel, Inhuman or Degrading Treatment or Punishment.(2)

- People who are in prison have the same right to health care as everyone else

- Health care staff must deal with prisoners primarily as patients and not prisoners

- Health care staff must have the same professional independence as their professional colleagues who work in the community

- Health policy in prisons should be integrated into National Health Policy ${ }^{(3)}$

\section{SUBSTITUTION TREATMENT IN PRISONS}

- All forms of drug dependence treatment influence the risk of HIV transmission. But substitution treatment programmes have the greatest potential to reduce injecting drug use and the resulting risk of spread of infection

- The most common form of substitution treatment is methadone maintenance treatment. Methadone has been used to treat heroin and other opiate dependence for decades. It have been proven to greatly reduce the risk of HIV infection.

- This type of treatment available to prisoners has the potential of reducing injecting and syringe-sharing in prisons. In addition, prisoners participating in methadone maintenance treatment have lower readmission rates than those not participating.

- Continuity of care is required to maintain the benefits of methadone maintenance treatment

- Before starting the treatment the drug user should be informed about the primary physician's obligations to the state, to the prison and to the prisoner. ${ }^{(4)}$

\section{MENTAL HEALTH}

- Mental health is the major part of general health and well being, Mental disorders and suicide are highly prevalent in prisons

- Provide psychological support to inmates and facilitate the good mentally healthy behaviors deliver to the society

- The safeguard is in place when all prison personnel are carefully selected and adequately trained in reducing mental harm and promoting mental health

- It is vital that prisons cooperate with community agencies to secure equality and continuity of mental health care ${ }^{(5)}$

- Early identification of suicidal risk factors and counseling to the inmates under low self esteem and risk of 
- under low self esteem and risk of depressive disorder

\section{DENTAL HEALTH}

- Having a good dental health is as important for prisoners as it is for the rest of the population

- Prisons should offer a comprehensive dental health care service based on patients clinical needs

- Prison should provide an appropriate range of dental services ${ }^{(6)}$

- A large percentage of the prison population enter prison with poor oral health

- Untreated disease among prisoners is greater than general population from similar social back grounds

- Prison administrators should be aware of and responsive to the dental health needs of different prison populations.

- Dental attendance among prisoners is less than general population

- To recognize dental services as an integral part of comprehensive health services for prisoners. (7)

\section{SPECIAL HEALTH REQUIREMENTS FOR FEMALE PRISONERS.}

- Female prisoners have complex needs, particularly with regard to their physical and mental health

- Many female prisoners have mental health, substance misuse and self-injury problems. Health care services in prison are needed that take into account the gender-specific issues and problems these women face. ${ }^{(8)}$

- Staff working in women prisons should be aware of the particular risks of self-harm among women in custody

- It is estimated that at least $75 \%$ of women arriving in prison have some sort of drugrelated problem at the time of arrest.

\section{HUMAN RIGHTS IN PRISON}

- Right to physical and moral integrity

- Right to an adequate standard of living

- Making prisons as a safe place

- Instruments of restraint shall never be applied as a punishment

- Non discrimination

- Women in prison- women prisoners shall be detained separately from male prisoners

- Juveniles in detention

- Life and long term prisoners- every human being has the inherent right to life, which shall be protected by law Non-custodial Measures, the use of non-custodial measures should be recommended and encouraged.(10)

\section{REFERENCES:}

1. WHO Regional Office for Europe (1999). Mental health promotion in prisons:

a consensus.

(http://www.euro.who.int/prisons/p ublications/20050610_1, accessed 15 September 2006)

2. Health in Prison, A view of Primary Health Care ,A WHO guide to the essentials in prison health edited by: Lars Møller, Heino Stöver,Ralf Jürgens, Alex Gatherer and HaikNikog

3. Center for prisoner health and human rights, Standards and protocols

,Miriam Hospital, the albert medical School of Brown University.

4. Dooris M. Healthy Settings: Challenges to generating the Treatment strategies,. Health Promotion International Journal, 21(1):55-65

5. Prison Service Order 3200- Mental Health Promotions, London, HM Prison service for England and wales, 2013

6. Hayton P, Van den Bergh B, Dental Health Protection in Prison, The Madrid recommendation, Public Health, 2010, 124(11) 635-636 